\title{
A Dream of the Ring: The Great Jack Johnson
}

I'll be the first

to chase the white hope

from coast to coast

corner him at last

\& buckle his knees

Rednecks in Reno

will check in their guns

$\&$ drop their ducats

to watch the sun gleam

from my teeth my dark muscles

my great bald head

Vamps \& debs will blush \& giggle

as they watch me train

will prance into paradise with me

carve their lives in my back

kill themselves

knead my heart like dough

Hate will snag me

jail me for crossing state lines

$\&$ being a man

I'll fight bulls in Madrid

Griots will feed me to their children

to make them strong

My jabs \& hooks

sweat \& knockouts

my derbies long cars \& gall

will live forever

I'll have one rag of a time

when I become Jack Johnson 